\title{
Pengenalan Bentuk Geometri bagi Anak Usia Dini dan Sekolah Dasar Kelas Rendah Melalui Origami
}

\author{
Silfanus Jelatu ${ }^{1}$, Maria Lim $^{2}$, Maria Yasinta Ngoe $^{3}$ \\ 1,2,3 STKIP Santu Paulus
}

\begin{abstract}
Article History ABSTRACT
Received 04.04.2019

Received in revised form 30.05.2019

Accepted 26.07.2019

Available online 20.08.2019

INTRODUCTION TO THE GEOMETRY FORM OF EARLY AGE CHILDREN AND LOW-CLASS SCHOOL THROUGH ORIGAMI. Geometry is one of the subjects of mathematics taught from elementary school to the upper secondary level and continued in college. Geometry is also a mathematical subject that has a relationship with the real world or the world that is close to students. Introducing geometry to children is not necessary when children are in formal education, but they can get closer to geometry early. Limitation of geometry that can be given to early childhood is only on form recognition. The process is different, namely by entering the world of children or the world of the play. One that is relevant to accommodating this process is origami. Therefore, the purpose of this community service activity is to introduce geometric forms to early childhood through the game of origami. This activity was carried out in the village of Urang, Kec. Melak Kab. Manggarai NTT. The method used in this PKM activity is training that begins with a presentation. The results obtained from this activity indicate a change in choosing a game, as well as the existence of basic geometric abilities that can recognize geometric shape objects.
\end{abstract}

KEYWORDS: Geometry, Origami. Attribution 4.0 International License, which permits unrestricted use, distribution, and reproduction in any medium, provided the original work is properly cited. (c) 2019 Silfanus Jelatu, Maria Lim, Maria Yasinta Ngoe.

\section{PENDAHULUAN}

Geometri merupakan salah satu topik penting dalam pembelajaran matematika. Pembelajaran geometri dikatakan penting karena banyak topik dalam pembelajaran matematika seperti kalkulus, dan lain-lain ditopang oleh geometri. Selain itu, geometri diklaim sebagai komponen penting dari belajar matematika karena memungkinkan siswa untuk menganalisis dan menafsirkan dunia tempat mereka tinggal serta memahami kegunaannya untuk dapat diterapkan di bidang ilmu lainnya (Jelatu, Sariyasa, \& Ardana, 2018).

\footnotetext{
${ }^{1}$ Corresponding author: Program Studi Pendidikan Matematika STKIP Santu Paulus, Jl. A. Yani No 10 Ruteng, Flores, NTT, Indonesia
} Email: silfanusjelatu@yahoo.co.id 
Membangun pemahaman tentang konsep geometri merupakan satu hal yang penting dilakukan. Sebagaimana yang diungkapkan Maarif (2015) bahwa salah satu kemampuan yang harus dimiliki siswa dalam mempelajari geometri adalah membangun pengetahuan tentang konsep dan prinsip-prinsip geometri baik datar maupun ruang dari perspektif formal dan informal.

Namun, beberapa kajian menunjukan bahwa sebagian siswa masih mengalami kesulitan dalam membangun pemahaman konsep geometri. Susilawati, Suryadi, \& Dahlan (2017) menjelaskan bahwa pemahaman terhadap konsep geometri yang kurang disebabkan oleh kemampuan visual yang kurang. Dengan kata lai pemahaman geometri dapat dioptimalkan apabila siswa memiliki kemampuan visual spasial yang baik. Kemampuan ini berkaitan dengan kemampuan mengenali bentuk objek geometri baik datar maupun ruang.

Menurut Canturk Gunhan (2014), melibatkan proses kognitif visualisasi dan penalaran adalah alur untuk memperoleh pemahaman konsep geometri (pemikiran geometrik). Visualisasi adalah keterampilan yang membantu siswa untuk mengenali dan membuat bentuk atau objek baru, dan mengungkapkan hubungan di antara mereka. Sedangkan geometric reasoning mengacu pada tindakan menciptakan dan menggunakan sistem konseptual formal untuk menyelidiki bentuk dan ruang.

Kedua proses kognitif ini dapat ditingkatkan melalui metode pembelajaran serta kebiasaan untuk berkolaborasi dengan dunia visual. Namun, salah satu langkah konkret dan penting dilakukan adalah menumbuhkan pengalaman spasial dan pengetahuan geometri di usia pra sekolah atau saat usia dini. Memperkenalkan bentuk geometri kepada anak sejak dini merupakan solusi yang dapat dilakukan. Memasukan geometri ke dalam dunia anak merupakan salah satu jalan mengembangkan kemampuan spasial anak.

Dunia anak identik dengan bermain atau aneka permainan. Salah satu permainan atau kegiatan yang bisa diajarkan kepada anak-anak adalah origami. Menurut sejarah (Akayuure, Asiedu-Addo, \& Alebna, 2016), kata "origami" berasal dari dua kata Bahasa Jepang yakni "Oru" dan "Kami" pada tahun 1880. Origami merupakan seni melipat kertas (FOLDing of PAPER) yang diakui sebagai tujuan agama dan estetika di Korea, Chinese and Japanese. Namun, nilai pedagogis origami menjadi tersebar luas setelah Yoshizawa Akira, grandmaster origami, menggunakan teknik origami dalam mengajarkan konsep-konsep geometris kepada pekerja pabrik. Buku pertamanya, Atarashi Origami Geijutsu (Seni Origami Baru) diterbitkan pada tahun 1954. Setelah periode Meiji (1868-1912), beberapa buku tentang teknik origami diterbitkan dan para peneliti memulai studi empiris pada matematika origami. Dalam upaya mengglobalisasi dan membuat matematis origami, Konferensi Internasional pertama tentang Origami Sains, Matematika, dan Pendidikan diadakan pada 1989 di Ferrara, Italia, konstruksi origami Huzita terkenal dibahas .

Dalam beberapa penelitian yang telah dilakukan (Arici \& Aslan-Tutak, 2005; Fenyvesi, Budinski, \& Lavicza, 2014; Golan, 2011), mereka menemukan bahwa penggunaan origami dalam pengajaran dapat mempromosikan pemikiran planar siswa, kemampuan penalaran spasial dan analitik. Hal ini menjadi dasar dalam membangun pemahaman geometri. Boakes (2009) mencatat bahwa aktivitas origami menghasilkan instruksi yang multi-modal dalam bentuk mode pembelajaran visual, verbal dan kinestetik. 
Penelitian tentang pembelajaran mengungkapkan bahwa lingkungan belajar multi-modal seperti itu mempromosikan penalaran geometris yang efektif di antara siswa dengan gaya belajar yang berbeda (Canturk Gunhan, 2014). Hasil kajian ini menyiratkan bahwa penggunaan origami dapat membantu siswa untuk memvisualisasikan, bernalar, dan menemukan sifat dasar bentuk termasuk hubungan geometris dan transformasi diantara objek geometris.

Dari beberapa literatur yang penulis temukan, penelitian tentang pemanfaatan origami tampaknya terkonsentrasi di sekitar masalah kognitif dengan sedikit fokus pada aspek afektif seperti sikap siswa dan guru. Mayoritas studi kontemporer tentang instruksi origami sebagian besar berfokus pada kemampuan spasial, penalaran geometris, pengetahuan geometris dan prestasi geometris siswa. Sebagai contoh, Cakmak, Isiksal, \& Koc (2014) melihat efek instruksi origami pada kemampuan spasial. Hasilnya menunjukkan peningkatan yang signifikan dalam keterampilan visualisasi spasial di antara siswa di kelas empat, lima, dan enam setelah menggunakan pengajaran origami. Mereka menyelidiki efek instruksional berbasis origami pada keterampilan dan persepsi spasial siswa sekolah dasar. Studi mereka menemukan bahwa instruksi origami memiliki efek positif pada skor kemampuan spasial siswa dan prestasi belajar geometri.

Penelitian sebelumnya oleh Arici \& Aslan-Tutak (2005) menyelidiki efek instruksi origami pada kemampuan spasial siswa sekolah menengah di Turki serta terhadap keterampilan visualisasi, pengetahuan geometris, dan pencapaian geometris. Menurut mereka, instruksi origami secara substansial bermanfaat bagi siswa. Di Isreal, penelitian tentang program origametria pada tahun 2009-2010 oleh Isreali Origami Center mengungkapkan bahwa siswa dapat lebih memahami, mengenali, dan mendefinisikan istilah dan bentuk ketika kegiatan origami dimasukkan dalam pelajaran matematika. Secara khusus, kegiatan origami disimpulkan dapat membantu guru-guru khususnya guru sekolah dasar dalam mengajar murid-murid mereka. Origami bagi anak pra-sekolah dan sekolah dasar mengakomodasi perkembangan mereka sesuai dengan teori Van Hiele yakni mengakomodasi level 0 (visualisasi) dan 2 (abstraksi) pemikiran geometris (Golan, 2011). Sebuah studi oleh Fenyvesi et al (2014) tentang menghubungkan origami dan GeoGebra di Sekolah Menengah di Serbia melaporkan bahwa origami memungkinkan siswa untuk tidak hanya membayangkan atau melihat objek dalam gambar atau lingkungan virtual tetapi juga merasakan objek yang dibuat. Studi yang mereka buat lebih lanjut mengungkapkan bahwa siswa dapat memperoleh solusi untuk masalah geometri yang kompleks. Sebaliknya, sebuah penelitian di Amerika melaporkan perbedaan yang secara statistik tidak signifikan dalam aspek pengetahuan geometris siswa antara siswa pada kelompok kontrol dan kelompok eksperimen yang menggunakan instruksi origami (Boakes, 2009).

Georgeson (2011) mencatat bahwa origami mungkin tidak bermanfaat jika guru mengizinkan siswa untuk memikirkan aspek kesenangan dari kegiatan origami. Di indonesia, Lisnani (2017) dalam penelitiannya yang berjudul "Desain Materi Bangun Datar Menggunakan Origami Berkonteks Tangram di SD Kelas II" berhasil menghasilkan produk pembelajaran berbasis origami dan dari hasil uji efektifitasnya menunjukan bahwa penggunaan media berbasis origami dapat meningkatkan kemampuan komunikasi siswa khususnya pada materi bangun datar.

Menilik pada hasil penelitian di atas, maka penulis mencoba memperkenalkan permainan origami ini kepada anak usia dini dan siswa sekolah dasar kelas rendah untuk 
menumbuhkan pengalaman awal mereka terhadap dunia geometri. melalui kegiatan ini, penulis berharap agar para anak usia dini mengalami kemudahan dalam beajar geomteri saat memasuki usia sekolah dasar. Permasalahan prioritas yang harus diatasi dalam masyarakat tersebut adalah belum diperkenalkannya inovasi dalam pemanfaatan sarana permainan kreatif berupa origami dalam meningkatkan pengetahuan tentang bentuk geometri kepada anak usia dini.

\section{METODE PELAKSANAAN}

Kegiatan pengabdian kepada masyarakat ini dilaksanakan pada tanggal 1-25 Agustus 2018. Kegiatan dilakukan di desa Urang, Kecamatan Lelak, Kabupaten Manggarai, Nusa Tenggara Timur. Metode yang digubakab dalam pelaksanaan kegiatan PKM ini adalah metode pelatihan berupa demonstrasi dan pendampingan. Adapun tahapan kegiatannya terdiri dari tahap perencanaan, tahap persiapan, tahap pelaksanaan, dan tahap evaluasi.

Tahap perencanaan, kegiatan-kegiatan yang dilakukan pada tahap perencanaan adalah: Pembentukan tim PkM dan Diskusi program kegiatan PkM. Tim yang bertanggung jawab untuk melaksanakan kegiatan pengabdian kepada masyarakat terdiri dari satu orang dosen dan tiga Mahasiswa. Tim PkM yang telah dibentuk, selanjutnya melakukan diskusi dengan kepala desa yang menjadi sasaran kegiatan PkM serta masyarakat tentang masalah yang mereka hadapi dalam pendampingan putra-putrinya dalam belajar terutama dalam belajar matematika dan menjelaskan program PkM yang akan dilakukan. Kegiatan diskusi tersebut dilakukan pada bulan Juli tahun 2018.

Tahap persiapan, kegiatan-kegiatan yang dilakukan pada tahap persiapan adalah penyusunan program pendampingan, beserta pembuatan dan perlatihan anggota tim. Selanjutnya melangkah pada tahap pelaksanaan. Tindakan dalam kegiatan tahap pelaksanaan ini berupa implementasi program.

Tahap evaluasi. Selama kegiatan berlangsung tim PkM juga melakukan evaluasi terhadap proses pelaksanaan oleh tim kepada masyarakat sasaran. Evaluasi dilakukan terhadap keberhasian pelaksanaan kegiatan. Evaluasi dilakukan terhadap peningkatan kemampuan anak-anak dalam melakukan origami berbentuk Geometri. Kegiatan ini berupa: (1) pemberian kertas baru yang masih utuh, lalu meminta anak melipat sesuai instruksi. (2) Siswa diberikan gambar geometri lalu diminta untuk menyebutkan nama dari gambar yang dimaksud. Hasil yang ditemukan menunjukan bahwa siswa mampu berkereasi bentuk geometri melalui origami serta mampu membedakan bentuk-bentuk geometri berdasarkan bentuk yang digambar.

\section{HASIL DAN PEMBAHASAN}

Mitra dari kegiatan PkM ini yaitu anak-anak usia dini dan siswa sekolah dasar kelas rendah di desa Urang Kecamatan lelak. Informasi dari kepala desa dan orang tua menyatakan bahwa sebagian besar anak-anak usia sekolah dasar belum pernah memanfaatkan waktu bermain di luar jam sekolah untuk belajar. Mereka lebih banyak menghabiskan waktu di luar sekolah untuk bermain permainan tradisional. Selain itu, berdasarkan informasi dari kepala desa bahwa di Desa Urang belum ada program Pendidikan Anak Usia Dini (PAUD). 
Beberapa gambaran tentang kondisi desa Urang memotivasi penulis untuk melakukan sebuah kegiatan yang berguna bagi masyarakat desa Urang khususnya anak usia dini siswa sekolah dasar kelas rendah. Selain itu, penulis berharap melalui kegiatan yang akan dilakukan anak-anak di desa Urang tidak mengalami disparitas pemahaman yang tinggi dengan anak-anak di Kota atau di desa Lain yang memiliki fasilitas pengembangan kognitif anak usia dini siswa sekolah dasar kelas rendah. Adapun kegiatan yang berhasil dirancang untuk diaplikasikan di desa Urang adalah melakukan pelatihan permainan origami atau seni melipat kertas. Penulis mengerucut kegiatan yang dilakukan khusus pada aspek pengenalan bentuk geometri sebagai dasar untuk memepersiapkan anak dini mengikuti pelajaran matematika di Sekolah Dasar yakni pada kelas tinggi.

Setelah semua kegiatan perancangan dan persiapan dilakukan. Tim PkM selanjutnya menjelaskan program beserta gambaran kegiatan yang akan dilakukan dengan kepala desa dan para orang tua. Hasil pertama yang diperoleh adalah berupa respon positif dari mereka yang selanjutnya mewajibkan kepada kepada anak-anak mereka untuk berpartisipasi dalam kegiatan.

Selama kegiatan PkM berangsung anak-anak begitu antusias karena menganggap kegiatan origami berbentuk geometri merupakan salah satu permainan baru bagi mereka. Permainan ini pula dianggap berkaitan dengan pelajaran matemaika di sekolah. Beberapa orang tua juga tidak terbatas pada motivasi agar anak mengikuti kegiatan, tetapi mereka juga ikut mengawasi partisipasi anak mereka selama kegiatan. Beberapa diantara orang tua pun ikut berpartisipasi dalam kegiatan karena dianggap bisa dijadikan sebagai guru yang akan melatih mereka apabila tim PkM tidak berada di lokasi kegiatan.

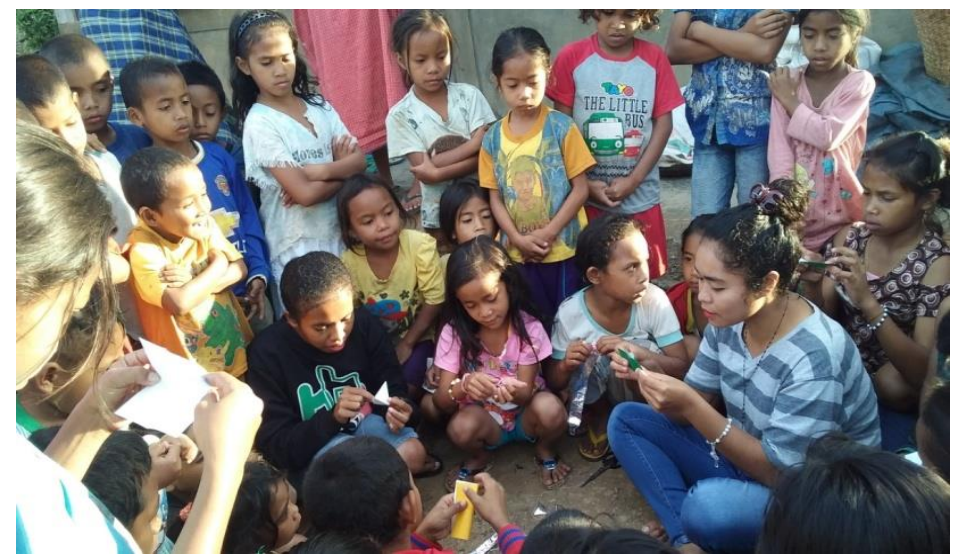

Gambar 1. Latihan Pembuatan Origami

Selama kegiatan berlangsung tim PkM juga melakukan evaluasi terhadap proses pelaksanaan kegiatan kepada masyarakat sasaran. Evaluasi dilakukan terhadap keberhasian pelaksanaan kegiatan. Evaluasi dilakukan terhadap peningkatan kemampuan anak-anak dalam melakukan origami berbentuk Geometri. Kegiatan ini berupa: (1) pemberian kertas baru yang masih utuh, lalu meminta anak melipat sesuai instruksi. (2) Siswa diberikan gambar geometri lalu diminta untuk menyebutkan nama dari gambar yang dimaksud. Hasil yang ditemukan menunjukan bahwa siswa mampu berkereasi bentuk geometri melalui origami serta mampu membedakan bentuk-bentuk geometri berdasarkan bentuk yang digambar. 


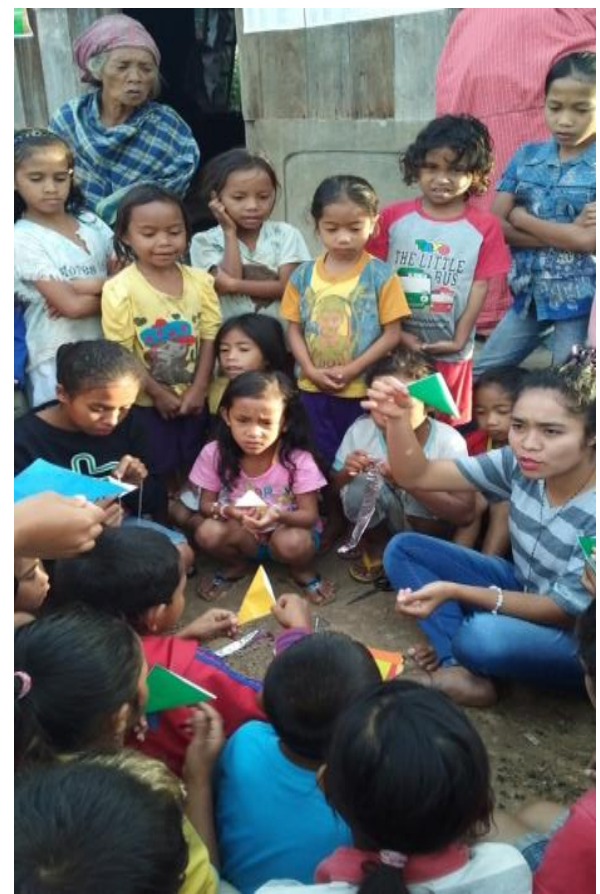

Gambar 2. Hasil Kegatan Origami Berbentuk Segitiga

Pada saat melakukan evaluasi tim PkM menilai ketercapaian kegiatan dari aspek kecepatan dan ketepatan menjawab pertanyaa. Dari hasil pengamatan yang dilakukan saat evaluasi sebagian besar anak dapat menjawab beberapa pertanyaan dengan cepat dan benar. Mereka bahkan mampu mengenal bentuk-bentuk geometri pada benda-benda nyata yang ada di sekitar mereka maupaun dalam bentuk gambar yang diatayangkan oleh penulis. Namun, ada beberapa anak yang menunjukan ketepatan saja tetapi lambat dalam menjawab. Mengingat hampir $90 \%$ dari peserta dapat menunjukan kecepatan dan ketepatan dalam menjawab, maka kami berkesimpulan bahwa kegiatan PKM ini berhasil. Hal ini didukung oleh kesimpulan atas penelitian yang dilakukan Pinho, Delou, \& Lima (2016) bahwa origami adalah fitur yang sangat bagus dan menyenangkan dan efisien untuk membahas konsep-konsep geometris dan elemen-elemennya.

Hasil kegiatan ini diyakini juga dapat menanamkan pemahaman tentang geometri yang akan bertahan dalam waktu yang sangat lama dalam ingatan anak. Dalam konteks pembelajaran di sekolah formal, Obi, Agwagah, \& Agah (2014) melalui penelitian yang dilakukan menunjukan bahwa penggunaan origami sebagai pendekatan pembelajaran secara signifikan meningkatkan retensi siswa dalam geometri bila dibandingkan dengan pendekatan pembelajaran konvensionalnya. Demikian pula, penggunaan origami terbukti lebih unggul daripada instruksi konvensional dalam mempromosikan retensi siswa yang sama dalam konsep geometri yang diajarkan.

\section{SIMPULAN}

Khalayak sasaran dari pengabdian ini adalah anak-anak usia 4-8 tahun di desa Urang, Kecamatan Lelak, Kabupaten Manggarai. Kegiatan dilaksanakan pada tanggal 1215 Agustus 2018 yang bertempat di halaman kantor desa Urang. Dari hasil evaluasi diperoleh hasil dan manfaat dari kegiatan pengabdian ini diantaranya adalah 
meningkatkan kemampuan anak dalam mengenal bentuk objek geometri. Kegiatan pengabdian ini berjalan dengan lancar, karena berbagai pendukung diantaranya adalah partisipasai kepala desa dan orang tua terutama partiipasi peserta yang cukup antusias dan berpartisipasi aktif dalam kegiatan ini.

\section{REFERENSI}

Akayuure, P., Asiedu-Addo, S. K., \& Alebna, V. (2016). Investigating the effect of origami instruction on preservice teachers' spatial ability and geometric knowledge for teaching. International Journal of Education in Mathematics, Science and Technology, 4(3), 198. doi: $10.18404 /$ ijemst.78424

Arici, S., \& Tutak, F. A. (2013). Using origami to enhance geometric reasoning and achievement. In Eighth Congress of European Research in Mathematics Education (CERME 8), Antalya, Turkey.

Boakes, N. J. (2009). Origami Instruction in the Middle School Mathematics Classroom: Its Impact on Spatial Visualization and Geometry Knowledge of Students. RMLE Online, 32(7), 1-12. doi: 10.1080/19404476.2009.11462060

Cakmak, S., Isiksal, M., \& Koc, Y. (2014). Investigating effect of origami-based instruction on elementary students' spatial skills and perceptions. The Journal of Educational Research, 107(1), 59-68. doi: 10.1080/00220671.2012.753861

Gunhan, B. C. (2014). A case study on the investigation of reasoning skills in geometry. South African Journal of Education, 34(2), 1-19. doi: 10.15700/201412071156

Fenyvesi, K., Budinski, N., \& Lavicza, Z. (2014). Two Solutions to an unsolvable problem: connecting origami and geogebra in a Serbian high school. In Proceedings of the $17 \mathrm{Th}$ Bridges International Conference (pp. 95-102).

Georgeson, J. (2011). Fold in Origami and Unfold Math. Mathematics Teaching in the Middle School, 16(6), 354-361.

Golan, M. (2011). Origametria and the van Hiele theory of teaching Geometry. Origami, 5, 141-150. doi: 10.1201/b10971-15

Jelatu, S., Sariyasa, S., \& Ardana, I. M. (2018). Effect of geogebra-aided REACT strategy on understanding of geometry concepts. International Journal of Instruction, 11(4), 325336. doi: 10.12973/iji.2018.11421a

Lisnani, L. (2017). Desain materi bangun datar menggunakan origami berkonteks tangram di SD Kelas II. Suska Journal of Mathematics Education, 3(1), 33-40. doi: 10.24014/sjme.v3i1.3504

Maarif, S. (2015). Mengkonstruksi bukti geometri melalui kegiatan eksplorasi berbantu Cabri II Plus. Jurnal Euclid, 3(2), 517-539. 
Obi, D. C. N., Agwagah, P. U. N. V, \& Agah, D. J. J. (2014). Effect of origami on students' retention in geometry. IOSR Journal of Research \& Method in Education (IOSRJRME), 4(5), 46-50. doi: 10.9790/7388-04514650

Pinho, T. M. M., Delou, C. M. C., \& Lima, N. R. W. (2016). Origami as a tool to teach geometry for blind students. Creative Education, 7(17), 2652-2665. doi: 10.4236/ce.2016.717249

Susilawati, W., Suryadi, D., \& Dahlan, J. A. (2017). The Improvement of mathematical spatial visualization ability of student through Cognitive Conflict. Mathematics Education, 12(2), 155-166. 